\title{
GENERAL DENTAL PRACTITIONERS' CONFIDENCE IN PERFORMING MOLAR ROOT CANAL, TREATMENT
}

M. Abdullah, ZA. Che Ab Aziz, R. Saub, $N$ Murat, E. Sulaiman, N. Hashim, NH. Mohamad Azmi. General Dental Practitioners Confidence In Performing Molar Root Canal Treatment. Annal Dent U.nlv Malaya 2009; 16.' $9-14$.

\section{ABSTRACT}

The objectives of this study were to assess the practice of molar root canal treatment (RCT) among general dental practitioners (GDPs), confidence level of GDPs in performing molar RCT and to identify factors that influence their confidence in managing molar RCI.'. One hundred questionnaires were distributed to GDPs in Kuala Lumpur and Selangor., Fifty questionnaires were delivered by mail and the remaining fifty were hand-delivered. All data was coded and verified. Fiftysix OOPs rcsponded to the questionnaires. Only fortyfive questionnaires were accepted $(n=45)$ as eleven OOPs had never performed molar RCI. . Most of the OOPs followed the standard quality guidelines while performing molar RCT except for vitality testing $(36.4 \%)$ and rubber dam usage $(27.3 \%)$. In this study, $100 \%$ of the GDPs were confident in making diagnosis of perinidicular diseases and $95.4 \%$ were confident in performing molar RCT from history taking until obturation... Patients' tolerance and availability of instruments and materials $(97.7 \%)$ were two factors that most influence the GDPs' confidence level. The least influcncing factor was undergraduate training $(78.1 \%)$. Attending seminars and lectures on endodontic, large number of molar teeth treated for ReT, patLents' affordability to pay for RCT and postgraduate training also influencc GDPs' confidence to a certain degree. From this study, it can be concluded that majority of OOPs complied standard quality guidelines except for vitality testing and rubber dam usage. Most of them were confident in performing molar RCT and were greatly influenced by the availability or instruments and materials in their clinic and patients' tolerance in receiving molar RCI.'.

Key words: general dental practitioner; molar root canal treatment; confidence

\section{INTRODUCTION}

Root canal treatment (RCT) or endodontic treatment is the removal of inflamed and/or infected pulp tissue from the root canal system, thus maintaining or returning the health of the periradicular tissues. (I.). Dental caries, tooth fracture, tooth surface loss and

\section{Original Article}

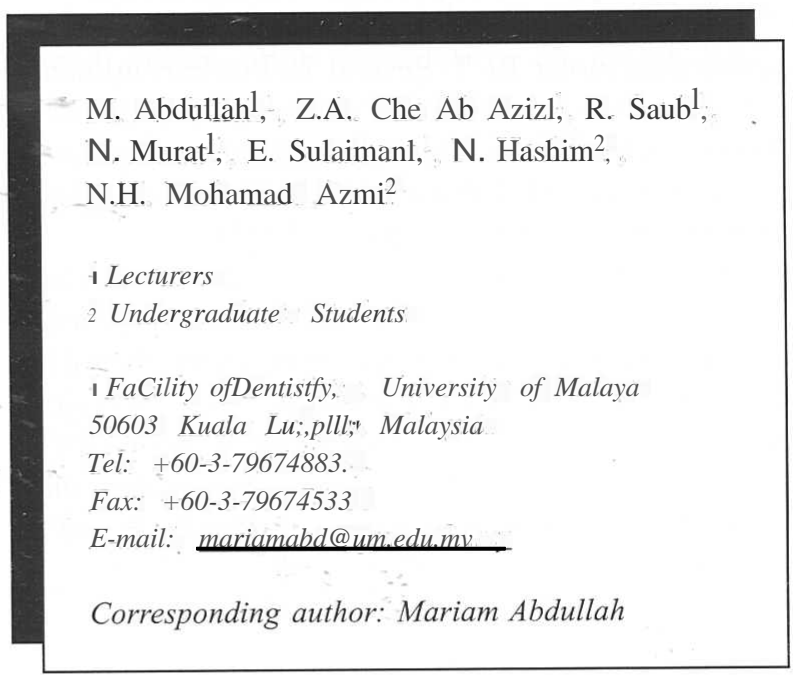

microleakage around restoration are among some common reasons for performing RCT (2).

According to Bjorndal et al (2) the most common root treated teeth were molars. Commonly applied techni<jues quoted in studies for molar RCT are stepback, step-down, crown down and'd6uble-flared techniques $(3,4)$. These te,chniques can remove bulk of microorganisms which harbour at the coronal aspect of root canal,

Asepsis is very important during molar RCT procedures to ensure treatment success. Rubber dam has been used for many decades to achieve this condition (5) . Rubber dam isolation is mandatory in RCT to prevent accidental swallowing of root canal instruments, prevent saliva and bacterial contamination, protect patients from irrigants and improv'e visual access. However, in a study by Jenkins et al less than $19 \%$ of the GDPs used rubber dam routinely and $44.5 \%$ said they never used rubber dam (6).

A myriad of endodontic instruments are available in the market to prepare root canals. From the conventional stainless stcel files, there are now files made of nickel titanilJm, either hand or rotary, to overcome the limitations of stainless steel files.

Sodium hypochlor)te had been the chemical irrigant of choice as it has antimicrobial property and can dissolve organic debris (6). Other jrrigants reported include normal saline, chlorhexidine and local anesthetic (7). With the increased knowledge and better understanding of the root canal infection and the importance of applying intracanal medicament, many OOPs prefer to perform multiple visits RCT (8) Tntracanal medicament has been proved to eliminate microorganisms from the root canal (9). Calcium hydroxide had been advocated as the most widely used intracanal mcdicament $(1 \mathrm{O})$. 
Study has proven that good coronal seal is as important as apical seal (11). Thcrefore, postendodontic restoration should be carried out as soon as possible. ComJ11on types of restoration include amalgam, Nayyar core, post and core and crown.

Confidence of the GDPs is essential when performing molar RCT. Several factors can influence the confidence level of GDPs in managing molar RCT. Patient factors, knowledge of the dentists, number of molar teeth treated, and availability of hands-on courses on molar RCT had been implicated (12).

With the advent of new root canal materials, instruments, techniques and medicaments, the practice of molar RCT and confidence level among the GDPs varies greatly. This study was conducted to investigate the practice of molar RCT employed by the GDPs in Kuala Lumpur and Selangor areas, to evaluate their confidence level in performing molar RCT and to identify factors that influence their confidence in managing molar RCT.

\section{MATERIALS \& METHODS}

\section{The questionnaire}

This study is a cross-sectional study designed to assess the GDPs' confidence in performing molar RCT A self-administercd questionna,ire was used to obtain information and the questionnaire was devcloped based on the literature review.

The questionnaire consisted of five maig sections. Section A consisted of five questions regarding GDP's gel!der, ethnic origins, year of graduation, schools or' graduation,- specialties, service period and type of practice. Section B comprised of experience in performing molar RCT including average number of molar root canal treatment performed annually. Section C consisted of eighteen questions involving the procedures in making the correct diagnosis, the GDPs' opinion on those procedures and what were the most commonly used materials and techniques. Section D consisted of thirteen questions regarding GDPs; confidence level in obtaining diagnosis and tr ating periradicular diseases and their overall confidence in performing molar RCT from history taking until obturation. The last section of this questionnaire consisted of seven questions regarding facto $\mathrm{s}$ influencing GDPs' confidence level in managing molar RCT.

\section{Pre-test survey}

A pre-test of the questionnaire was conducted prior to the actual survey to test for ambiguity, content validity and reliability. A pilot study was conducted among postgraduate students of Faculty of Dentistry, University of Malaya. Ten subjects had participated in this pre-test and all of them understood all the questions.
The subjects and survey

One hundred GDPs in Kuala Lumpur and Selangor areas were selected to participate in this survey. Fifty questionnaires with the cover letters were delivered by mail and the remaining fifty were hand-delivered. The respondents were given three to four weeks to reply to the questionnaires. Self-addressed mail envelopes were enclosed with the questionnaires delivered by mail.

All collected data was later coded and entered into a database for calculation of percentages.

\section{RESULTS}

\section{Socio-demog:raphic characteristics}

Of one hundred questionnaires distributed, fifty six GDPs replied eventually. Eleven questionnaires were discarded as the GDPs had never performed molar RCT, giving a total sample of forty five GDPs $(n=45)$. There were twenty four males and twenty females in the study sample (one respondent missed a question on gender), with Malay; 42.2\%, Chinese; $35.6 \%$, Indian; $17.8 \%$ and Punjabi; $2.2 \%$.

$67.4 \%$ of the GDPs graduated from local universities, mainly from University of Malaya. ;34.1\% graduated between 1997 and 2006 and only 9.1\% graduated between 1967 and 1976. 56.8\% graduated between 1977 and 1996. Two GDPs continued their study to postgraduate level and specialized in Master in Clinical Dentistry. Figure 1 shows the clinical experience of the GDPs.

\section{Molar RCT experience}

Figure 2 shows the average number of molar RCT completed per year by the GDPs. In this study, $40.5 \%$ of the GDPs completed only about one to twenty molar RCTs per year.

\section{Molar RCT practice}

The most common complaint from patient seeking molar RCT was pain. (63.5\%), followed by sleep disturbance (15.9\%), unable to eat properly (11.1\%) and (ractured tooth $(9.5 \%)$.

Majority of the GDPs inquired medical history from their patients (86.4\%) and performed extra-oral 'examination (77.3\%) before performing molar RCT.

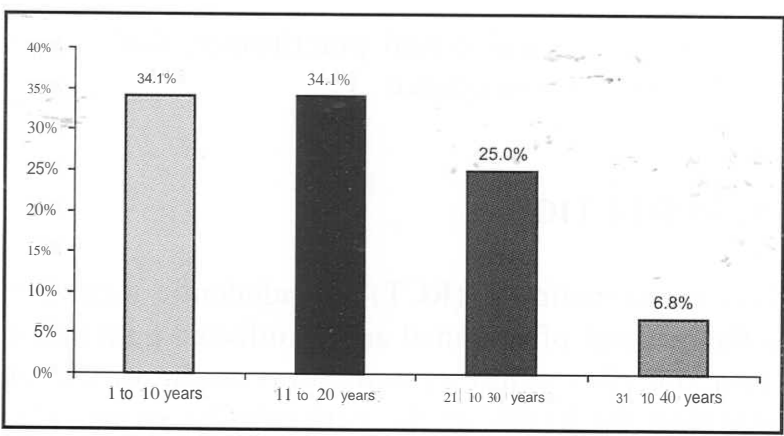

Figure 1. Clinical experience of the GDPs. 


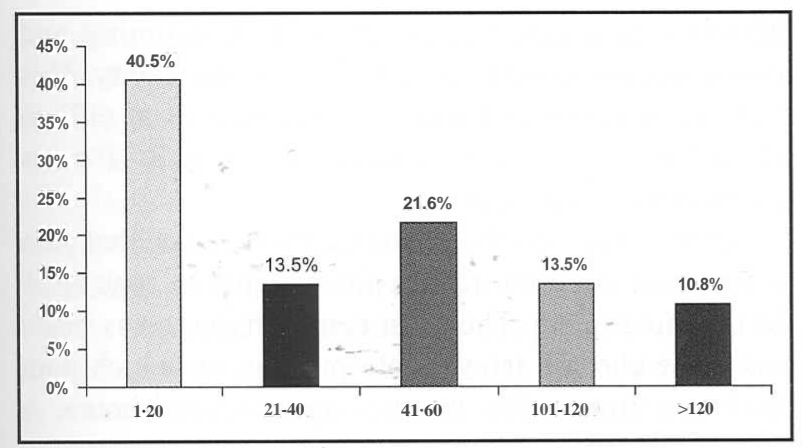

Figure 2. Average number of molar RCT completed per year by the GOPs.

More than $90 \%$ of the GDPs performed intra-oral examinations such as inspection, palpation, percussion and mobility test. $74.4 \%$ of the GDPs took radiographs before and during the treatment, and only a small percentage $(36.4 \%)$ of GDPs performed vitality tests prior to performing molar RCT. Only $27.3 \%$ of GDPs used rubber dam during RCT of the molar teeth. Majority of the molar teeth were root canal treated due to acute/chronic irreversible pulpitis (64.4\%) followed by pulp necrosis (18.6\%), acute/chronic apical periodontitis (15.3\%) and periapical abscess (1.7\%). All GDPs (100\%) agreed that history taking, extra and intra-oral examinations, radiographs and vitality tests before indicating a molar RCT were useful in making a diagnosis.

K-file (32.4\%) was the most common root canal instrument used for molar RCT whereas Hedstroem $(5.6 \%)$ was the )east common instrument used. In this study, 52\% of the GDPs opted to use crown down technique when they prepared the canals while $34 \%$ of them preferred to use step back technique. Whereas, $14 \%$ of them indicated that step down technique was their technique of choice for root canal preparation. Sodium hypochlorite (51.9\%) remained as the most common irrigating solution used while performrng. molar RCT. The remaining GDPs, $48.1 \%$, used other types of irrigants such as normal saline, local anesthetic solution, chlorhexidine, EDTA or distilled water.

With increased knowledge about root canal infection, $77.5 \%$ of the GDPs indicated that they utilized more than two visits for molar RCT. However, $22.5 \%$ of the GDPs needed only two visits to complete molar RCT. Calcium hydroxide $(53.8 \%)$ was the most common intracanal medicament used between each visit. The remaining, $38.5 \%$ of the GDPs chose to use other types of medicament such as formaldehyde, phenolic compound, cresophine, endopaste, Ledermix, creosote, formocresol, and polyantibiotic cream. In this study, $7.7 \%$ of the GDPs reported that they never used any intracanalmedicament between visits.

Cold lateral compaction remained the most common obturation technique for $53.1 \%$ of the GDPs followed by warm lateral compaction (26.5\%), warm vertical compaction (18.4\%) and carrier-based system $(2.0 \%)$. This study showed that $78.3 \%$ of the GDPs preferred to use zinc oxide eugenol as the temporary filling between visits. In contrast, the remaining GDPs, $21.7 \%$ preferred to use other types of filling materials such as intermediate restorative material (IRM) and Cavit.

In this study it was found that $41.8 \%$ of the GDPs placed crown upon completion of molar RCT. Conversely, $27.3 \%$ of the GDPs placed amalgam filling only, and $14.5 \%$ of the GDPs placed post and core and crown after completion of molar RCT.

RetreatInent was not common among the GDPs, with only $17.5 \%$ of the GDPs performed süch treatment.

In our study, $100 \%$ of the GDPs were confident in history taking, performinll intraoral examination and making diagnosis of pulp and peri radicular diseases. Only a single respondent (2.6\%) was not confident in taking radiograph and two respondents (5.9\%) were not confident in performing vitality tests. $95.4 \%$ of the GDPs were confident in performing molar RCT from history taking until obturation procedures. From the total subjects, $76.9 \%$ of GDPs were confident in applying the rubber dam. More than 90\% of the GDPs were confident in preparing access cavities, finding root canals, determining working length, performing. root canal preparation, using irrigating solutions and obturating root cana1s (Table I).

The two most influencing factors in perfprming molar RCT by GDPs were the avail bility of instruments and materials in the clinic and patients' tolerance, both $97.7 \%$ each. The least influencing factor was the undergraduate training (78.1\%) (Table 2).

\section{DISCUSSION}

The low response rate $(45 \%)$ in this study could be due to the lack of cooperation from the GDPs in completing and returning the questionnaires. Other reasons include incomplete or change of addresses and inadvertent loss of questionnaires in the post. Therefore, caution should be exercised in generalizing the finding to reflect the practice of GDPs in performing molar RCT. Nevertheless, this is a descriptive study which could possibly help in obtaining some insight regarding the confidence of GDPs in performing molar root canal treatment.

Most of the GDPs involved in this survey were local graduates. However, none of them specialized in the field of endodontics. Thus their knowledge, clinical skills, materials and techniques were based on undergraduate knowledge together with clinical experiences.

The small number $(40.5 \%)$ of molar RCT cornpleted per year (one to twenty) by the GDPs could possibly be due to high technical demands in performing molar root canal treatment. Molar RCT requires high clinical skills and adequate equipments and materials. Other technical difficulties exist such as 
Table 1. Confidence level of GDPs in performing molar RCT

\begin{tabular}{|c|c|c|}
\hline Data & $\begin{array}{l}\text { Confidence } \\
\text { Level }\end{array}$ & $\begin{array}{l}\text { Percentage } \\
\text { (\%) }\end{array}$ \\
\hline History taking & $\begin{array}{l}\text { Confident } \\
\text { Not Confident }\end{array}$ & $\begin{array}{c}100 \% \\
-\end{array}$ \\
\hline Intraoral examination & $\begin{array}{l}\text { Confident } \\
\text { Not Confident }\end{array}$ & $\begin{array}{c}100 \% \\
-\end{array}$ \\
\hline Radiograph taking & $\begin{array}{l}\text { Confident } \\
\text { Not Confident }\end{array}$ & $\begin{array}{c}97.4 \% \\
2.6 \%\end{array}$ \\
\hline Vitality testing & $\begin{array}{l}\text { Confident } \\
\text { Not Confident }\end{array}$ & $\begin{array}{c}94.1 \% \\
5.9 \%\end{array}$ \\
\hline Making diagnosis & $\begin{array}{l}\text { Confident } \\
\text { Not Confident }\end{array}$ & $\begin{array}{c}100 \% \\
-\end{array}$ \\
\hline Rubber dam isolation & $\begin{array}{l}\text { Confident } \\
\text { Not Confident }\end{array}$ & $\begin{array}{l}76.9 \% \\
23.1 \%\end{array}$ \\
\hline Access , cavity & $\begin{array}{l}\text { Confident } \\
\text { Not Confident }\end{array}$ & $\begin{array}{c}93.3 \% \\
6.7 \%\end{array}$ \\
\hline Finding root canals & $\begin{array}{l}\text { Confident } \\
\text { Not Confident }\end{array}$ & $\begin{array}{l}91.2 \% \\
8.8 \%\end{array}$ \\
\hline Determine working length & $\begin{array}{l}\text { Confident } \\
\text { Not Confident }\end{array}$ & $\begin{array}{c}93.3 \% \\
6.7 \%\end{array}$ \\
\hline Root canal preparation & $\begin{array}{l}\text { Confident } \\
\text { Not Confident }\end{array}$ & $\begin{array}{c}95.6 \% \\
4.4 \%\end{array}$ \\
\hline Use of irrigation & $\begin{array}{l}\text { Confident } \\
\text { Not Confident }\end{array}$ & $\begin{array}{c}95.6 \% \\
4.4 \%\end{array}$ \\
\hline Root canal obturation & $\begin{array}{l}\text { Confident } \\
\text { Not Confident }\end{array}$ & $\begin{array}{c}93.4 \% \\
6.6 \%\end{array}$ \\
\hline $\begin{array}{l}\text { Performing molar RCT from } \\
\text { history taking until obturation }\end{array}$ & $\begin{array}{l}\text { Confident } \\
\text { Not Confident }\end{array}$ & $\begin{array}{c}95.4 \% \\
4.6 \%\end{array}$ \\
\hline
\end{tabular}

Table 2. Factors influencing GDPs' confidence in performing molar RCT

\begin{tabular}{lcc}
\hline Factors & Response ? & $\begin{array}{c}\text { Percentage } \\
(\%)\end{array}$ \\
\hline Undergraduate training & Yes & $78.1 \%$ \\
& No & $21.9 \%$ \\
Postgraduate training & Yes & $78.7 \%$ \\
& No & $21.3 \%$ \\
Seminars and lectures & Yes & $90.7 \%$ \\
Availability of instruments & No & $9.3 \%$ \\
and materials & Yes & $97.7 \%$ \\
Patients' tolerance & No & $2.3 \%$ \\
& Yes & $97.7 \%$ \\
Patients' affordability & No & $2.3 \%$ \\
& Yes & $88.4 \%$ \\
Large number of molar & No & $11.6 \%$ \\
teeth treated & Yes & $90.5 \%$ \\
\hline
\end{tabular}

difficulty to locate the canals, time consuming and limited access to posterior part of the oral cavity. This study is in agreement with Che Ab Aziz et al (13) in which $74 \%$ of the GDPs tend to limit their RCT cases to anteriors and premolars.

In this study, $63.5 \%$ of the GOPs reported that pain as the most common reason for patients to seek RCT for the molar teeth. The most common diagnosis made was acute/chronic irreversible pulpitis, in which pain can linger from a few minutes up to several hours. A study by Bjorndal et al (2) stated that the most common aetiology for molar teeth requiring RCT was caries which exposed the pulp and eventually lead to toothache.

More than $70 \%$ of the GOPs took medical history, performed extra and intraoral examination and took radiographs of their patients requiring molar RCT. This is possibly because they were aware of the importance of these procedures in obtaining an accurate diagnosis and providing a proper treatment plan. Nevertheless, vitality tests were not widely done possibly due to the fact that these private clinics did not have an electric pulp tester.

Although rubber dam placement is strongly recommended as a standard during RCT procedures to provide isolation, protection and improve $\mathrm{v}\{$ sual access, only $27.3 \%$ of the GOPs reported using rubber dam. This is in agreement. with findings by Che Ab Aziz et al (13). Rubber dam usage was not popular among private GOPs because of additional time needed to place the rubber dam, poor patient acceptability, extra cost and lack of adequate skills or training in the rubber dam placement.

This study found that $32.4 \%$ of the GDPs preferred to use K-file, possibly due to the availability of this instrument in the market. In addition, it works effectively in root canal preparation especially in narrow canals such as those found in the molar tooth. In this study, $52 \%$ of the respondents mentioned that crown down technique were their choice of technique to prepare the canals. This could be due to the increased availability of nickel titanium type of root canals instruments in the market. Besides, $34.1 \%$ of the respondents were graduated within the last ten years (1997-2006) and could possibly have more and better exposure in learning and acquiring crown down technique using $\mathrm{NiTi}$ instruments. According to Saunders et al (12), crown down technique allows irrigant to penetrate deeper into tl! . canals providing an effective irrigation. Tn addition, this technique. facilitates early removal of infected materials at the coronal aspect of the canal. Besides, it provides better instrument control and less dcbri extrusion apically. From this study, it was found that $51.9 \%$ of the GOPs used sodium hypochlorite as their irrigant of choice. This finding is concurred with two previous studies by Saunders et al (12) and Slaus and Bottenberg (14). Sodium hypochlorite is capable in producing an antimicrobial action and dissolving organic tissue. 
Distilled water was used as an irrigant only by one GDP. Distilled water is not a recommended irrigant since it has no antimicrobial property.

The main choice of intracanal medicament in this study was calcium hydroxide $(53.8 \%)$. It was favoured over Ledermix or phenolic compound since it is proven to reduce residual microbial flora (15), inactivate the effects induced by' endotoxin (16) and provide the longest protection against bacterial leakage (17). Due to a better understanding of the benefits of intracanal medicament and microbiological aspect of root canal infection (18), most GDPs practised multiple visits for the RCT of molar. Study by Slaus and Bottenberg (14) showed that most dentists required two treatment visits to complete molar RCT.

Obturation of root canal is performed following shaping and cleaning procedures. In this study, 53. I\% of GDPs chose cold lateral compaction as their technique of choice for obturation of the molar teeth. Finding in this study is in agreement with Jenkins et al. (6) and Siaus and Bottenberg (14). Cold lateral compaction is relatively simple and versatile technique that does not necessitate expensive equipments.

However, it has the disadvantages of potential root fracture if excessive force is applied and gutta percha wastage at the coronal aspect of the tooth.

Zinc oxide eugenol (ZOE) was the most commonly used temporary filling materials because it is relatively cheap compared to IRM or Cavit.. However, IRM and Cavit can provide better seal Jhan ZOE. Nevertheless, this study showed that all the GDPs used biocompatible temporary filling materials.

Our study found that crown was the restoration of choice for most GDPs following molar RCT. Root treated teeth usually have very little remaining tooth structure left resulting from extensive caries, fracture and previous restorations. - Thus the tooth is prone to fracture under occlusal load (19). Crown is capable in providing cuspal coverage for protection against fracture in a root treated tootli. However, only a small number of GDPs (14.5\%) built post and core prior to the crown preparation.

The finding of this study stated that few practitioners (17.5\%) performed retreatment cases. This finding is in agreement with study by Bjorndal et al. (2). This could possibly be due to the fact that most GDPs referred their retreatment cases to the specialists. In contrast, Siaus and Bottenberg (14) mentioned that $79.8 \%$ of the GDPs in their study performed retreatment cases because most patients prefer the general dentists possibly due to the fact that they can offer treatment at an affordable cost as compare to the specialists.

In this study, all GDPs were confident : in making diagnosis of pulp and periradicular diseases. This could possibly be due to previous undergraduate training in universities where students were taught to develop diagnostic skills extensively and accurately.
Most GDPs (95.4\%) were confident in performing molar RCT (from history taking until obturation). This is in agreement with the study by Saunders et al. (12). It could possibly because there are now newer and better root canal instruments, materials and techniques available which may facilitates in performing a root canal treatment... Nowadays, with an increasing patient's knowledge, there is an increase demand for root canal treatment as compare to tooth extraction. Thus, this Gould increase the experience, skills and knowledge of the GDPs, hence increases their confidence level in performing molar RCT.

Our study found that $23.1 \%$ of the GDPs were not confident in rubber dam placement. This could possibly because they were lacking in knowledge and skills in placing rubber dam (12). In addition, $6.7 \%$ and $8.8 \%$ of the respondents were not confident in accessing and finding root canals, respectively. This could be due to the variabilitY of the shape and location of canals. Besides, $6.7 \%$ of the GDPs were not confident in working length determination, possibly due to the fact that endodontic files may be displaced during radiographic procedures which may result in wrongly determined working length.. Moreover, $4.4 \%$ and $6.6 \%$ of the GDPs were not confident in performing root canal preparation and obturation of molar teeth respectively. They may be lacking in knowledge and skills especially in treating molar teeth \}vith complex root canal anatomy.

Majority of the GDPs '(97.7\%) felt that their confidence il managing molar RCT was greatly influenced by patients' tolerance and the availability of instruments and materials in the clinic. Another important factor was availability of seminars, lectures and hands-on courses. Our findings showed that $90.7 \%$ of the GDPs believed that frequent attendance to such courses could help to increase their knowledge in molar $\mathrm{RC}$; $\mathrm{T}$. In addition, $90.5 \%$ of the GDPs believed that by carrying out molar RCT at a larger scale annually, could possibly help them to acquire the necessary skills, techniques and knowledge. This is turn help to enhance their confidence level in performing molar RCT.

Majority (95.4\%) of our participants in this survey stated that they were highly confidence in performing molar root canal treatment:... However, caution should be exercise in interpreting the findings since a high confidence level does not necessarily imply that a good tre atment quality is provided.

\section{CONCLUSIONS}

YVithin the limitations of this study, the following conclusions could be drawn:

I. Majority of GDPs followed standard quality guidelines during molar RCT procedures except for vitality testing and rubber dam placement. 
2. Most GDPs were confident in gathering all the information and making diagnosis of pulp and periradicular diseases.

3. Most GDPs were confident in performing molar RCT from history taking until obturation.

4. Availability of instruments and materials in the clinic and patients' tolerance in receiving molar RCT were two factors that greatly influenced the GDPs' confidence in performing molar RCT.

5. The least influencing factor of GDPs' confidence in managing molar RCT was the undergraduate training.

\section{REFERENCES}

1) Manogue M, Patel S, Walker R. The Principles of Endodontics. 1st edn. United Kingdom, Oxford University Press 2005.

2) Bjorndal L, Laustsen MH, Reit C. Root canal treatment in Denmark is most often carried out in carious vital teeth and retreatments are rare. Int Endod J 2006; 39: 785-90.

3) Harty FJ, Endodontic treatment in England. Int Endod J 1984; 17: 106-]2.

4) Ahmed MF, Lelseed A, Ibrahim YE. Root canal treatment in general practice in Sudan.. Int Endod J 2000; 33: 316-19.

5) Elderton RJ. A modern approach to the use of rubber dam. Dent Prac'1971; 21: 187-93,226-32, 267-73.

6) Jenkins SM, Hayes SJ, Dummer PMH. A study of endodontic treatment carried out in dental practice within the UK. Int Endod J 200]; 34:16-22.

7) Ercan E, Ozekinci T, Atakul F, Gul K. Alltib,!cterial activity of $2 \%$ chlorhexidine gluconate and $5.25 \%$ sodium hypochlorite in infected root canal: in vivo study. J Endod 2004; 30: 84-7.

8) Randal L and Richard LC. One appointment endodontic therapy: An opinion survey. J Endod 1980; 6: 10: 799-80 I.
9) Siren EK, Haapasalo MP, Waltimo TM, Orstavik D. In vitro antibacterial effect of calcium hydroxide combined with chlorhexidine or iodine potassium iodide on Enterococcus faecalis. Eur J Oral Sci 2004; 112(4): 326-31.

10) Foreman PC, Barnes IE. Review of calcium hydroxide. Int Endod J 1990; 23(6): 283-97.

I]) Ray HA, Trope M. Periapical status of endodonticcally treated teeth in relation to the technical quality of root filling and the cor<!nal restoration. Int Endod J 1995; 28: 12-8.

12) Saunders WP, Chestnutt G, Saunders EM. Factors influencing the diagnosis and management of teeth with pulpal and periradicular disease by general dental practitioners, Part 1. BDJ 1999; 187: 49297.

13) Che Ab Aziz ZA, Abdullah M, Vello CDS, Thangavelu K. General dental practitioners' knowledge and practice on root canal treatment. Annals of Dent 2006; 13: ]2-17.

14) Slaus G, Bottenberg P. A survey of endodontic practice amongst Flemish dentists. Int Endod $\mathrm{J}$ 2002; 35: 759-67.

15) Law A, Messer H. An evidence-based analysis of the antibacterial effectiveness of intracanal medicaments. J Endod 2004; 30: 689-94.

16) Tanomaru JM, Leonardo MR, Tanomaru Filho M, et a!. Effect of different irrigation solutions and calcium hydroxide on bacterial LPS. Int Endod J 2003; 36: 733-9.

17) Barthel CR, Zaritzki FE, Raab WH, Zimmer S. Bacterial leakage in roots filled with different medicaments and sealed with Cavit. J Endod 2006; 32: $127-9$.

18) Wolch S. One appointment endodontic treatment. J Can. Dent Assoc 1975; 41:: 613-5.

19) David A, Joseph N, Varon G, et 111.Assessment of the resistance to fracture of endodontically treated molars restored with amalgam. J Prost Dent 2003; 89: $462-5$. 